\title{
HUBUNGAN ANTARA PENGETAHUAN DAN STATUS GIZI DENGAN KEJADIAN ANEMIA PADA REMAJA PUTRI DI KABUPATEN BADUNG
}

\author{
Putra, Kadek Agus Dwija \\ Akademi Keperawatan Kesdam IX/Udayana \\ *Korespondensi : agusdwija@ymail.com
}

\begin{abstract}
Background: The prevalence of anemia in adolescent girls in Indonesia according to WHO reaches $30 \%$, and in the 2013 Riskesdas report recorded $18.4 \%$ of adolescents have anemia with the highest percentage in the female sex of $23.9 \%$. Anemia in adolescents can cause delay in physical growth and behavior and emotional disorders. This study aims to determine the relationship between knowledge about anemia and nutritional status with the incidence of anemia in young women in Badung Regency. Method: This study uses analytic cross sectional design with a sample of 106 adolescent girls aged 15-18 years in high school, Badung Regency. Data collection was carried out directly on respondents in each school, for anemia data was collected by examining blood samples or hematology panels (hemograms) with an Hematology Autoanalyzer tool, data on knowledge of anemia was carried out by means of interviews using questionnaire guidelines, and nutritional status data was carried out by how to measure anthropometry (body weight and height) to get a IMT value. The analysis conducted is univariate analysis to determine the distribution and frequency of variables and bivariate analysis using the Kai-Kuadrat/Chi-Square test with the help of the SPSS program. Result: The prevalence of anemia in young women is $13.2 \%$. Most had normal nutritional status of $77.4 \%$, while others were categorized as abnormal / malnutrition (2.8\% thin, $17.0 \%$ fat, $2.8 \%$ obese). For the level of knowledge obtained, the majority of $77.4 \%$ have a good level of knowledge in the category of anemia. Kai-Square / Chi-Square test results showed that, there was a significant relationship between knowledge about anemia and anemia in adolescent girls (95\% CI: 1.93-20.77; $\mathrm{p}=0.003$ ). There was no significant relationship between nutritional status and anemia in adolescent girls $(\mathrm{p}=0.301)$. Conclusion: Poor knowledge about anemia is associated with the incidence of anemia in young women, whereas nutritional status is not related to the incidence in young women. It is expected that related parties make a policy regarding anemia screening and education activities especially for young women.
\end{abstract}

Keywords: Anemia; Knowledge; Nutritional status 


\begin{abstract}
ABSTRAK
Latar belakang: Prevalensi anemia pada remaja putri di Indonesia menurut WHO mencapai 30\%, dan pada laporan riskesdas tahun 2013 tercatat 18,4\% remaja mengalami anemia dengan persentase tertinggi pada jenis kelamin perempuan yaitu sebesar $23,9 \%$. Anemia pada remaja dapat menyebabkan keterlambatan pertumbuhan fisik dan gangguan perilaku dan emosional. Penelitian ini bertujuan untuk mengetahui hubungan antara pengetahuan tentang anemia dan status gizi dengan kejadian anemia pada remaja putri di Kabupaten Badung. Metode: Penelitian ini menggunakan design cross sectional analitik dengan jumlah sampel 106 remaja putri usia 15-18 tahun di sekolah menengah atas, Kabupaten Badung. Pengumpulan data dilakukan langsung pada responden di masing-masing sekolah, untuk data anemia dikumpulkan dengan cara pemeriksaan sampel darah atau panel hematologi (hemogram) dengan alat Hematologi Autoanalyzer, data pengetahuan tentang anemia dilakukan dengan cara wawancara menggunakan pedoman kuesioner, dan data status gizi dilakukan dengan cara pengukuran antropometri (berat badan dan tinggi badan) untuk mendapatkan nilai IMT. Analisis yang dilakukan yaitu analisis univariat untuk mengetahui distribusi dan frekuensi variable dan analisis bivariat menggunakan uji Kai-Kuadrat/Chi-Square dengan bantuan program SPSS. Hasil: Prevalensi anemia pada remaja putri diperoleh sebesar $13,2 \%$. Sebagian besar memiliki status gizi normal yaitu 77,4\%, sedangkan lainnya masuk dalam kategori tidak normal/malnutrisi (kurus 2,8\%, gemuk 17,0\%, obesitas 2,8\%). Untuk tingkat pengetahuan diperoleh sebagian besar $77,4 \%$ memiliki tingkat pengetahuan dalam kategori baik tentang anemia. Hasil uji Kai-Kuadrat/Chi-Square menunjukkan bahwa, terdapat hubungan yang signifikan antara pengetahuan tentang anemia dengan anemia pada remaja putri (95\%CI:1,93-20,77; $\mathrm{p}=0,003)$. Tidak ada hubungan yang signifikan antara status gizi dengan anemia pada remaja putri $(\mathrm{p}=0,301)$. Simpulan: Pengetahuan yang kurang baik tentang anemia berhubungan dengan kejadian anemia pada remaja putri, sedangkan status gizi tidak berhubungan dengan kejadian pada remaja putri. Diharapkan pihak terkait membuat suatu kebijakan tentang kegiatan skrining dan edukasi anemia khususnya pada remaja putri.
\end{abstract}

Kata kunci: Anemia; Pengetahuan; Status gizi

\title{
PENDAHULUAN
}

Remaja putri adalah kelompok populasi yang rawan terhadap anemia karena sangat rentan mengalami defisiensi gizi akibat perubahan pola makan. Menurut penelitian di beberapa negara salah satunya di India, sekitar 56\% remaja putri rentan terhadap anemia (Dambal \& Panneerselvam, 2018). Begitu juga pada penelitian di rumah sakit Denizli, Turkey menemukan sebanyak 59\% remaja putri usia 12-16 tahun mengalami anemia (Balci, Karabulut, Gurses, \& Covut, 2012). Di Indonesia 
berdasarkan data riskesdas 2013 prevalensi anemia pada remaja putri usia 5-14 tahun 26,4\% dan usia 15-24 tahun 18,4\% (Badan Penelitian dan Pengembangan Kesehatan Kementrian Kesehatan RI, 2013).

Berdasarkan beberapa penelitian, faktor pengetahuan merupakan determinant anemia pada remaja putri namun sampai saat ini hasil yang ditemukan masih belum konsisten. Penelitian di Kabupaten Kudus mendapatkan pengetahuan tentang anemia berhubungan dengan anemia pada remaja putri (Farida, Widajanti, \& Pradigdo, 2013). Namun hal yang berbeda ditemukan pada penelitian di Pulewali Mandar yang memperoleh tidak ada hubungan antara pengetahuan dengan kejadian anemia pada remaja putri (Hapzah \& Yulita, 2012).

Selain faktor pengetahuan, faktor status gizi juga diperoleh hasil yang belum konsisten. Pada sebuah penelitian didapatkan hasil bahwa anak yang obesitas memiliki risiko 2 kali lebih tinggi menderita anemia (Nead, Halterman, Kaczorowski, Auinger, \& Weitzman, 2004). Hasil yang berbeda diperoleh pada penelitian di Bekasi yaitu remaja berstatus gizi kurus berisiko 8 kali lebih besar menderita anemia dibandingkan remaja putri berstatus gizi gemuk dan remaja berstatus gizi normal berisiko 6 kali lebih besar menderita anemia dibandingkan remaja berstatus gizi gemuk (Arumsari, 2008). Hal yang berbeda didapatkan pada penelitian di Semarang yang mendapatkan bahwa tidak ada hubungan bermakna antara status gizi dengan kejadian anemia pada remaja putri pada penelitian yang dilakukan di Sekolah Menengah Pertama Negeri 9 Semarang (Indartanti \& Kartini, 2014).

Tujuan penelitian ini dilakukan untuk mengetahui hubungan pengetahuan tentang anemia, konsumsi tablet tambah darah, persepsi citra tubuh, kebiasaan minum teh saat makan dan volume menstruasi terhadap anemia pada remaja putri.

\section{METODE}

Rancangan penelitian menggunakan cross sectional analitik yang dilaksanakan di SMA di Kabupaten Badung dari bulan Desember 2017 s.d Mei 2018. Sejumlah 106 orang remaja putri berusia 15-18 tahun dipilih menggunakan teknik cluster random sampling dari populasi terjangkau yang telah memenuhi kriteria 
inklusi yaitu, telah mengalami menstruasi, mendapatkan izin orangtua/wali, dan bersedia menjadi responden dan menandatangani inform consent. Proses pengumpulan data dilakukan langsung di masing-masing sekolah, untuk data status anemia diukur dengan pemeriksaan sampel darah atau panel hematologi (hemogram) memakai alat Hematologi Autoanalyzer, data status gizi dikumpulkan dengan cara pemeriksaan antropometri meliputi pengukuran berat badan dan tinggi badan untuk mendapatkan nilai indeks massa tubuh/IMT, sedangkan data pengetahuan tentang anemia dikumpulkan dengan cara wawancara menggunakan pedoman kuesioner yang sebelumnya sudah dilakukan uji validitas dan reliabilitas. Data pada penelitian ini dikategorikan menjadi 2 kategori yaitu pengetahuan (pengetahuan baik dan kurang baik), status gizi (status gizi normal dan status gizi tidak normal). Data dianalisis secara univariat, bivariat menggunakan uji chi square, dan multivariat menggunakan regresi logistik, untuk memperkirakan odds ratio dan 95\% confidence interval (CI). Penelitian ini telah mendapatkan kelaikan etik dari lembaga Komisi Etik Penelitian (KEP) Fakultas Kedokteran Universitas Udayana/Rumah Sakit Umum Pusat Sanglah Denpasar Nomor: 851/UN14.2.2/PD/KEP/2018.

\section{HASIL}

Berdasarkan analisis univariat diperoleh sebanyak 13,2\% remaja putri di SMA Kabupaten Badung mengalami anemia. Tabel 1 menunjukkan bahwa rata-rata umur $( \pm$ SD) adalah $16,37( \pm 0,68)$ tahun, dengan kategori terbanyak pada remaja awal sebesar 55,7\%. Pada pemeriksaan antropometri dan status gizi diperoleh nilai ratarata BB pada sampel adalah 52,37 kg, TB 156,97 cm dan IMT 21,26 dengan kisaran masing-masing 34,1-84 Kg, 142-172 cm, dan 15,59-34,44. Sebagian besar sampel memiliki status gizi normal yaitu $77,4 \%$ dan lainnya masuk dalam kategori tidak normal/malnutrisi (kurus 2,8\%, gemuk 17,0\%, dan obesitas 2,8\%). Hasil yang diperoleh pada variabel pengetahuan tentang anemia menunjukkan bahwa sebagian besar sampel $77,4 \%$ memiliki tingkat pengetahuan baik tentang anemia. Skor pengetahuan responden berkisar antara 12-28, dengan nilai rata-rata \pm SD yaitu 20,57 $\pm 4,24$ (95\%CI:19,75-21,38). Berdasarkan analisis data pada faktor pengetahuan 
diperoleh pengetahuan kurang baik sampel terdapat pada kurangnya pengetahuan tentang penyebab anemia dan jenis makanan yang banyak mengandung zat besi.

Hasil uji chi square mendapatkan bahwa terdapat hubungan yang signifikan antara pengetahuan tentang anemia dengan anemia pada remaja putri (95\%CI:1,9320,77; p=0,003) sebanyak $6(7,3 \%)$ remaja putri berpengetahuan baik mengalami anemia, sedangkan diantara remaja putri berpengetahuan kurang baik, ada $8(33,3 \%)$ remaja putri yang mengalami anemia. Berdasarkan hasil uji statistik pada variabel status gizi diperoleh bahwa tidak ada hubungan yang signifikan antara status gizi dengan anemia. Dari hasil analisis hubungan antara status gizi dengan kejadian anemia diperoleh $9(11 \%)$ remaja putri dengan status gizi normal mengalami anemia, sedangkan diantara remaja putri dengan status gizi tidak normal, ada $5(20,8 \%)$ remaja putri yang mengalami anemia, seperti tersaji pada Tabel 2.

Tabel 1 Distribusi Responden Berdasarkan Determinan Anemia $(\mathrm{n}=106)$

\begin{tabular}{|c|c|c|}
\hline Variabel & Jumlah (n) & Presentase $(\%)$ \\
\hline \multicolumn{3}{|l|}{ Umur } \\
\hline $12-16$ th (remaja awal) & 59 & 55,7 \\
\hline $17-25$ th (remaja akhir) & 47 & 44,3 \\
\hline Mean \pm SD & $16,3 \pm 0,7$ & \\
\hline \multicolumn{3}{|c|}{ Status anemia (Hemoglobin/Hb) } \\
\hline Tidak anemia & 92 & 86,8 \\
\hline Anemia & 14 & 13,2 \\
\hline \multicolumn{3}{|l|}{ Pengetahuan tentang anemia } \\
\hline Pengetahuan baik & 82 & 77,4 \\
\hline Pengetahuan kurang baik & 24 & 22,6 \\
\hline \multicolumn{3}{|l|}{ Status gizi } \\
\hline Kurus & 3 & 2,8 \\
\hline Normal & 82 & 77,4 \\
\hline Gemuk & 18 & 17,0 \\
\hline Obesitas & 3 & 2,8 \\
\hline Total & 106 & 100 \\
\hline
\end{tabular}

Tabel 2 Analisis Bivarita Determinan Anemia $(\mathrm{n}=106)$

\begin{tabular}{cccc}
\hline Variabel & Anemia & Tidak anemia & \multirow{2}{*}{ Nilai $\boldsymbol{p}$} \\
\cline { 2 - 3 } & $\mathbf{n}(\boldsymbol{\%})$ & $\mathbf{n}(\boldsymbol{\%})$ & \\
Pengetahuan tentang anemia & $8(33,3)$ & $16(66,7)$ & \multirow{2}{*}{0,003} \\
Pengetahuan kurang baik & $6(7,3)$ & $76(92,7)$ & \\
Pengetahuan baik & $5(20,8)$ & $19(79,2)$ & \multirow{2}{*}{0,301} \\
Status gizi & $9(11,0)$ & $73(89,0)$ & \\
Tidak normal & & & \\
Normal & &
\end{tabular}




\section{PEMBAHASAN}

Dalam penelitian ini diperoleh prevalensi anemia pada remaja putri di Kabupaten Badung sebesar 13,2\%, dan jika mengacu pada standar WHO termasuk dalam kategori ringan (WHO, 2011). Hasil ini lebih rendah dibandingkan dengan penelitian sebelumnya yaitu prevalensi anemia pada remaja putri di Kabupaten Badung sebesar 30\% (Widarini, 2008). Hal ini dikarenakan perbedaan pada populasi dan alat ukur, pada penelitian Widarini populasinya adalah remaja putri vegetarian dengan metode cyanmethemoglobin. Sedangkan pada penelitian ini populasinya adalah remaja putri secara umum dengan metode pemeriksaan panel hematologi menggunakan Hematologi Autoanalyzer.

Pada variable pengetahuan diperoleh, terdapat hubungan antara pengetahuan tentang anemia dengan anemia pada remaja putri (95\%CI:1,93-20,77; p=0,003). Hal ini sejalan dengan penelitian yang dilakukan di Kabupaten Banjar bahwa, responden dengan tingkat pengetahuan kurang tentang anemia memiliki peluang 8,750 kali untuk menderita anemia (Anggraini, Husaini, \& Khairiati, 2017). Hal ini juga didukung pada presentase uji statistik variabel pengetahuan menunjukkan kecenderungan yang mendukung hipotesis, seperti ada perbedaan cukup tinggi antara variabel pengetahuan dengan anemia pada remaja putri. Sebanyak $7,3 \%$ remaja putri dengan pengetahuan baik mengalami anemia, sedangkan diantara remaja putri dengan pengetahuan kurang baik 33,3\% remaja putri mengalami anemia. Pengetahuan dapat mengubah perilaku dan sikap yang kemudian akan melahirkan kesadaran diri dalam memilih bahan makanan yang sehat dan bergizi (terutama sumber zat besi) dan menghindari makanan dan minuman yang dapat menghambat penyerapan zat besi (Anggraini et al., 2017).

Hasil penelitian ini juga memperoleh bahwa tidak terdapat hubungan antara status gizi dengan anemia pada remaja putri $(\mathrm{p}=0,301)$. Hal ini sejalan dengan penelitian yang dilakukan di SMP Negeri 9 Semarang yang mendapatkan bahwa tidak ada hubungan bermakna antara status gizi dengan kejadian anemia pada remaja putri (Indartanti \& Kartini, 2014). Tidak signifikannya status gizi terhadap anemia pada penelitian ini mungkin dipengaruhi karena kesalahan dalam pengkategorian 
status gizi atau karena sebagian besar sampel memiliki status gizi normal, yaitu sebesar 77,4\% dan sisanya termasuk dalam kategori tidak normal/malnutrisi (kurus $2,8 \%$, gemuk $17 \%$, dan obesitas 2,8\%). Makanan yang banyak mengandung zat besi adalah bahan makanan yang berasal dari daging hewan (Arisman, 2009), dan pada penelitian ini diperoleh sebanyak 98,1\% sampel mengkonsumsi lauk hewani atau makanan yang berasal dari daging hewan. Selain banyak mengandung zat besi, serapan zat besi dari sumber makanan tersebut mempunyai angka keterserapan sebesar 20-30\%. Kekurangan zat besi merupakan faktor utama dari penyebab anemia gizi, dan kekurangan zat besi juga menjadi salah satu unsur penting dalam memproduksi hemoglobin. Kekurangan zat ini, bisa karena penderita memang kurang mengonsumsi makanan yang mengandung zat besi seperti sayuran hijau, ikan, hati, telur, dan daging. Serta mengkonsumsi makanan yang mengandung zat penghambat absorpsi zat besi dalam tubuh dalam waktu bersamaan (Citrakesumasari, 2012).

Penelitian ini memiliki beberapa keterbatasan antara lain, jumlah sampel yang sedikit dan lokasi penelitian dilakukan di Sekolah Menengah Atas/SMA, sehingga hasilnya tidak bisa digeneralisasi pada remaja putri dikomunitas.

Implikasi penelitian ini adalah diharapkan pihak terkait membuat suatu kebijakan mengenai pemberian edukasi kesehatan pada remaja usia sekolah, dan untuk peneliti selanjutnya diharapkan menggunakan jumlah sampel yang lebih banyak dengan populasi pada remaja di komunitas.

\section{SIMPULAN DAN SARAN}

Terdapat hubungan yang signifikan antara pengetahuan tentang anemia dengan kejadian anemia, dan tidak terdapat hubungan yang signifikan antara status

gizi dengan kejadian anemia pada remaja putri di kabupaten Badung. Diharapkan pihak terkait membuat kebijakan tentang pemberian edukasi khususnya anemia pada remaja putri usia sekolah. 


\section{UCAPAN TERIMA KASIH}

Terima kasih peneliti sampaikan kepada semua pihak yang telah membantu dalam pelaksanaan penelitian ini.

\section{DAFTAR PUSTAKA}

Anggraini, L., Husaini, \& Khairiati, L. (2017). The Correlation Of Menstrual Pattern and Knowledge Level About Anemia. Berkala Kesehatan Masyarakat Indonesia, 62. Retrieved from www.fk.jtam.unlam.ac.id/index.php/bkm/article/view/143

Arisman. (2009). Buku Ajar Ilmu Gizi “Gizi Dalam Daur Kehidupan.” Jakarta: EGC.

Arumsari, E. (2008). Faktor Risiko Anemia Pada Remaja Putri Peserta Program Pencegahan dan Penanggulangan Anemia Gizi Besi (PPAGB) Di Kota Bekasi. Institut Pertanian Bogor.

Badan Penelitian dan Pengembangan Kesehatan Kementrian Kesehatan RI. (2013). Riset Kesehatan Dasar Tahun 2013. Jakarta.

Balci, Y. I., Karabulut, A., Gurses, D., \& Covut, I. E. (2012). Prevalence and Risk Factors of Anemia among Adolescents in Denizli, Turkey. Iran J Pediatr, 22(1), 77-81.

Citrakesumasari. (2012). Anemia Gizi Masalah dan Pencegahannya (1st ed.). Yogyakarta: Kalika.

Dambal, S., \& Panneerselvam, S. (2018). Asian Pacific Journal of Nursing. Asian Pacific Journal of Nursing, 5(1)(January), 7-8.

Farida, I., Widajanti, L., \& Pradigdo, S. F. (2013). Determinan kejadian anemia pada remaja putri di Kecamatan Gebog Kabupaten Kudus tahun 2006. Retrieved July 31, 2018, from https://ejournal.undip.ac.id/index.php/jgi/article/view/6154

Hapzah, \& Yulita, R. (2012). Hubungan Tingkat Pengetahuan Dan Status Gizi Terhadap Kejadian Anemia Remaja Putri Pada Siswi Kelas III Di SMAN 1 Tinambung Kabupaten Polewali Mandar. Media Gizi Pangan, XIII(1), 20-25.

Indartanti, D., \& Kartini, A. (2014). Hubungan Status Gizi dengan Kejadian Anemia Pada Remaja Putri. Journal of Nutrition College, 3, 33-39. Retrieved from http://ejournals1.undip.ac.id/index.php/jnc

Nead, K. G., Halterman, J. S., Kaczorowski, J. M., Auinger, P., \& Weitzman, M. (2004). Overweight Children and Adolescents : A Risk Group for Iron Deficiency. Pediatrics, 114(1), 104-114.

WHO. (2011). Haemoglobin Concentration For the Diagnosis of Anemia and Assessment of Severity. Geneva. 
Widarini, N. P. (2008). Asupan zat gizi dan kejadian anemia pada remaja putri vegetarian di Kabupaten badung provinsi Bali. Universitas Gadjah Mada. 